
sistemas digitales*

\author{
Dynamic Visual Updates in digital systems
}

ID Esteban Gutiérrez-Jiménez ${ }^{* *}$

\title{
(1) $\Theta($
}

* Este artículo surge como resultado del proyecto en desarrollo Actualizaciones Visuales Dinámicas. Aprobado y financiado por el Departamento de Investigación y Postgrados de la Fundación Universitaria Bellas Artes. Código del proyecto PINV201802

** Docente investigador, Fundación Universitaria Bellas Artes. Miembro del Grupo de Investigación Creación FUBA, Medellín-Colombia. Email: investigacion.plasticas@bellasartesmed.edu.co

Fecha de recepción: 20 de junio de 2018

Fecha de aceptación: 18 de septiembre de 2018

\section{Cómo referenciar / How to cite}

Gutiérrez-Jiménez, E. (2019). Actualizaciones Visuales Dinámicas en los sistemas digitales. Trilogía Ciencia Tecnología Sociedad, 11(20), 17-38.

\section{https: / / doi.org/10.22430/21457778.1218}


Resumen: este artículo presenta el concepto Actualizaciones Visuales Dinámicas, para proponerlo como una herramienta conceptual en el estudio de las entidades visuales producidas y visualizadas en sistemas digitales. Ha sido desarrollado mediante el análisis de varias obras creativas que generan imágenes diversas producidas con sistemas digitales. Con un ejemplo gráfico, en el texto se identifican tres atributos de las imágenes digitales que permiten revisar diferencias estructurales y de lenguaje con relación a las creadas con procesos no digitales de construcción.

La presentación de una estructura informática básica, la definición de vectores diferenciales y de un marco de acción, permiten proyectar un modelo estructural que pretende aportar una herramienta de análisis que potencie sus características diferenciadoras en contraposición al concepto de imagen digital y su inevitable dependencia de lenguajes predigitales. Dicho modelo se articula con una aproximación materialista de los sistemas, según la cual es posible entender el software como material expresivo.

El texto explora las diferencias entre la imagen materia y la actualización visual. A continuación, implementa el modelo para revisar un archivo de fotografía digital, su estructura, su variabilidad y una serie de actualizaciones visuales posibles. Finalmente, se concluye que las estructuras informáticas que sustentan a las imágenes digitales son comunes a múltiples niveles de acceso a la información y a diferentes actualizaciones sensibles, lo cual permite plantear un campo de experimentación creativa donde el código es material y la imagen es proceso.

Palabras clave: imagen, material digital, creación, materialismos digitales.

Abstract: This article presents and proposes the concept of Dynamic Visual Updates as a tool to study visual entities produced and visualized in digital systems. It also analyzes several creative works 
that produce different images by means of digital systems. Using a graphic example, the text identifies three features of digital images that enable to examine structural and language differences compared to those created with non-digital processes.

The presentation of a basic computer structure as well as the definition of differential vectors and an action framework enable to devise a structural model that provides an analysis tool to boost its differentiating characteristics, as opposed to the concept of digital image and its inevitable dependence on predigital languages. Said model is articulated with a materialistic approach to systems, according to which software can be used as expressive material.

This work explores the differences between material images and visual updating processes. Subsequently, it adopts the model to review an archive of digital photographs, its structure, variability, and a series of possible visual upgrades. In conclusion, computer structures supporting digital images are common to multiple levels of access to information and different sensual updates, which enables to propose a field of creative experimentation where code is the material and the image is the process.

Keywords: image, digital material, creation, digital materialism. 


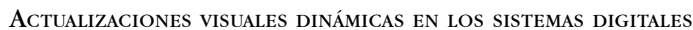

\section{CONTEXTUALIZACIÓN}

Actualizaciones visuales Dinámicas -AVD- es un concepto novel, propuesto como herramienta tecno-conceptual para el análisis de objetos visuales gestados en sistemas digitales; es complementado por un modelo que permite identificar los aspectos importantes en el proceso de creación de una imagen digital, para así identificar sus cualidades particulares. El desarrollo de las AVD se cimienta sobre tres investigaciones que han permitido una exploración técnico-programática, conceptual y creativa:

1. Dibujo: búsquedas y apropiaciones (Primera parte). Trabajo de especialización (Gutiérrez, 2006).

2. Dibujo: búsquedas y apropiaciones: Interfaces físicas (Segunda parte). Tesis de Maestría (Gutiérrez, 2007). ${ }^{1}$

3. Material digital y creación artística. Tesis de Doctorado (Gutiérrez, 2016).²

4. Actualizaciones Visuales Dinámicas. Proyecto Investigación-Creación (Gutiérrez, 2018). ${ }^{3}$

La primera exploración es un estudio práctico de las relaciones metodológicas entre el dibujo y la programación como sistemas para el desarrollo de pensamiento creativo. En esta investigación se produjeron una serie de herramientas de dibujo digital, para posteriormente implementarlas en la creación de un cuerpo extenso de obra gráfica. El dibujo: búsquedas y apropiaciones constituye un referente importante de la instancia metodológica, ya que en él se implementó en paralelo el desarrollo de las aplicaciones programáticas y el proceso de producción gráfica.

La segunda investigación da sustento teórico y conceptual a las AVD, como modelo analítico para las imágenes digitales. En Material digital y creación artística, se ha desarrollado el marco de acción en el que se proyecta la idea de un material

\footnotetext{
${ }^{1}$ Este proyecto se desarrolló en la Especialización en Diseño Multimedia (UNAL, 2006-07) y el Máster en Diseño Interactivo (MECAD, 2007-08). Consiste en la exploración del espacio del dibujo como instrumento de producción intelectual dentro de entornos digitales. Investigación realizada mediante el diseño, desarrollo y uso de una colección de aplicaciones digitales a través de las cuales se desarrollaron proyectos artísticos. Referencias: El dibujo: búsquedas y apropiaciones. Trabajo de especialización, Universidad Nacional y $D B A-E l$ cuerpo: interfaces físicas., Tesis de Maestría, Media Centre d'Art i Disseni (Barcelona).

${ }^{2}$ Tesis meritoria del Doctorado en Arte y Arquitectura de la Universidad Nacional de Colombia.

${ }^{3}$ Proyecto en desarrollo. Aprobado y financiado por el Departamento de Investigación y Postgrados de la Fundación Universitaria Bellas Artes.
} 
digital con el cual los creadores trabajan. Dentro de este contexto, la investigación se detiene en las actualizaciones visuales, es decir, en las imágenes digitales, para redefinir el modelo en función de ellas. La propuesta actual se centra en los resultados específicos que refieren a la imagen y el modelo que de ellos se desprende.

Por último, el tercer proyecto define un espacio para la creación visual mediante metodologías y conceptos propios de los sistemas digitales. En este contexto se han producido varios proyectos de producción audiovisual, para los cuales se diseñan y producen programas informáticos específicos que potencian y definen la exploración visual. Los resultados de estos procesos experimentales son actualizaciones visuales de las relaciones entre los programas, el proceso creativo y la transformación de los datos visuales.

\section{INTRODUCCIÓN}

\section{Las Actualizaciones Visuales Dinámicas}

(...) No existen las imágenes digitales o el sonido digital. Lo que llamamos una 'imagen digital' es un trozo de código que contiene las instrucciones de máquina para producir un flujo de electricidad con el que una pantalla analógica o una impresora analógica pueden desplegar una imagen (Cramer, 2001).

En la actualidad, las imágenes dominan el espectro de actualizaciones sensibles mediante las cuales se formaliza la información digital. Tanto en la cultura digital como en su infraestructura tecnológica abundan pantallas donde imagen y texto coexisten, interactúan e hibridan en un constante flujo de información visual. En ellas convergen medios que hasta hace unas décadas poseían estructuras tecnológicas, espaciales o socio económicas independientes y que tras su digitalización comparten un entorno informático común. Esta convergencia no consiste únicamente en compartir plataformas de distribución y consumo, más importante es la transformación y confluencia de los sistemas de codificación que facilitan el intercambio de datos y su mezcla. De allí que los objetos culturales que se proyectan en las pantallas digitales no puedan ser, consistentemente, catalogados, leídos ni descritos bajo los criterios de las imágenes tradicionales. 
El esfuerzo por entender e incluir en los estudios alrededor de la producción cultural, la abundancia de formas y potencias que adquiere la imagen dentro de los sistemas digitales es primordial para discernir qué dicen esas imágenes sobre el mundo. Diferenciar las metodologías, lenguajes y características de todos los medios que hoy convergen en las mismas pantallas digitales requiere de nuevos caminos de aproximación, ya que nos enfrentamos a entidades que se alejan de las estructuras lingüísticas y metodológicas de la imagen pictórica, del cine, de la fotografía o la televisión, entre otras.

La fuerza convergente de los sistemas digitales y sus pantallas puede generar la sensación de que sus actualizaciones visuales son herederas de la lógica de estos otros medios visuales ${ }^{4}$. Empero, su capacidad de contener y simular estas estructuras no debe obscurecerel hecho de que obedecen a un sistema informacional diferente, que tiende a expandir e hibridar a los medios predigitales. La aparente transparencia de los sistemas digitales esconde los procesos informáticos detrás de simulaciones que impiden el acceso a la 'realidad' computacional (Arns, 2013, p. 386). Este ocultamiento limita considerablemente el potencial de análisis sobre sus imágenes y formatea la manera en que las personas las usan y se expresan a través de ellas.

Es como parte de este esfuerzo que surge el concepto Actualizaciones Visuales Dinámicas (AVD) con el objeto de revisar la materialidad digital dentro del ámbito reducido de las imágenes que produce (Gutiérrez, 2016). En el actual artículo, se revisan las características que poseen las AVD y cómo estas se convierten en potencias expresivas que expanden y modifican el lenguaje visual contemporáneo.

\section{Definiciones y categorías}

La capacidad de abstraer, organizar, simbolizar y transmitir rápidamente grandes volúmenes de datos hace de las actualizaciones visuales herramientas eficaces para la interacción y comunicación entre los sistemas digitales y los humanos. Estos productos visuales cumplen una doble función: por un lado, son herramientas de interacción con la información digital, en forma de íconos, botones o listas. También, son vehículos de visualización en forma de modelos

\footnotetext{
${ }^{4}$ El concepto de convergencia como fuerza cultural utilizado en esta investigación es planteado por Henry Jenkins (2008). Por su parte, la idea de actualización como proceso de formalización del estado virtual de las entidades es expuesta por Pierre Lévy (1999).
} 
que mapean y hacen legibles cantidades indeterminadas de datos. Por otro lado, simulan imágenes predigitales, y sus lenguajes visuales, que son consumidas en entornos digitales. Esto es, se definen y actualizan como fotografías, videos, dibujos, cine, televisión, entre otras.

La primera función está asociada a las llamadas interfaces gráficas de usuario y a la visualización de datos. Estas actualizaciones visuales permiten ver e interactuar con los computadores, los programas informáticos y la información que circula en los sistemas digitales. Acá se concentra la mayor cantidad de objetos culturales considerados propios de la digitalización, pues han surgido y evolucionado con los propios sistemas. La segunda competencia de las actualizaciones visuales se relaciona generalmente con las denominadas imágenes digitales. Término que, en general, hace referencia a la digitalización de imágenes predigitales o a la producción digital de objetos visuales que se insertan en las estructuras culturales de sus predecesoras. Sin embargo, es importante comprender que todos los elementos visuales que emergen de los sistemas digitales tienen una naturaleza, una estructura y una lógica diferente a la de las imágenes tradicionales: la pictórica, la fotográfica y la electrónica. Tanto las interfaces gráficas como las imágenes digitales y otros objetos visuales emergentes tienen cualidades específicas de su condición digital, por lo que su separación y categorización dentro de los entornos digitales se relaciona con aspectos funcionales $u$ organizacionales, más que con diferencias reales de su estructura o sus atributos (Cramer, 2002).

Esto se debe a que las imágenes que se despliegan en una pantalla computacional hacen referencia a cadenas de valores numéricos que, tras una serie de procesos informáticos, se transforman en secuencias discretas de píxeles o puntos de color (Tanimoto, 2012). Esto implica que las formas proyectadas no están predeterminadas en la información a la que hacen referencia. Lo que vemos en pantalla es principalmente consecuencia del proceso actualizador del sistema y no exclusivamente de una información preinscrita en un archivo. En otras palabras, tanto la imagen digital como la interfaz gráfica son resultado de un proceso dinámico que involucra un conjunto de datos, diversos procedimientos informáticos, pantallas de proyección e interacción humana dentro de un sistema dinámico; si alguno de estos elementos está ausente la imagen no se da.

Siendo así, todos los objetos visuales son incluidos en este estudio bajo el concepto de: actualizaciones visuales dinámicas o AVD, pues se considera que 
esta perspectiva enfatiza las cualidades propias de su naturaleza digital y permite enfocar dichos atributos bajo el lente de sus imágenes. Las AVD son la instancia sensible (visual) para el hombre del sistema relacional datos-procesos-sistemahumano. Son la capa más externa del sistema donde toma forma, por un instante, el intercambio dinámico de fuerzas de actualización y virtualización del material digital y el pensamiento creativo.

\section{METODOLOGÍA}

AVD es un concepto útil para el análisis del proceso de creación-producción de las imágenes digitales y de sus características particulares o vectores diferenciales. Siendo así, ha sido desarrollado mediante metodologías de experimentación programático-creativa; análisis tecno-formal de proyectos artísticos de impacto nacional e implementación del modelo en procesos académicos y de investigación. Cada instancia investigativa se ha desarrollado en los proyectos citados en la contextualización de la investigación que, por su parte, han generado resultados dentro del ámbito artístico y académico.

Dibujo: búsquedas y apropiaciones conecta el trabajo gráfico con el desarrollo informático de forma efectiva, lo cual produce una convergencia entre las herramientas de producción, los procesos de creación y sus resultados visuales. Esto es, el proyecto se despliega mediante el desarrollo en paralelo de las herramientas informáticas de producción (programas) y la obra gráfica (imagen). En la Imagen 1 se presenta un proceso de dibujo digital mediante uno de los programas desarrollados en el proyecto, se puede ver la forma en que se entrelazan las capacidades técnicas del programa con las necesidades formales de la propuesta visual. Además, este proceso de diseño-desarrollo-experimentación fue de gran importancia para entender la correlación entre el material digital y su proyección visual en pantalla. Los desarrollos de este proyecto sentaron las bases para la posterior interpretación de la imagen como actualización sensible del código informático. 
Imagen 1. Cazador de miedos, Barcelona, 2008.
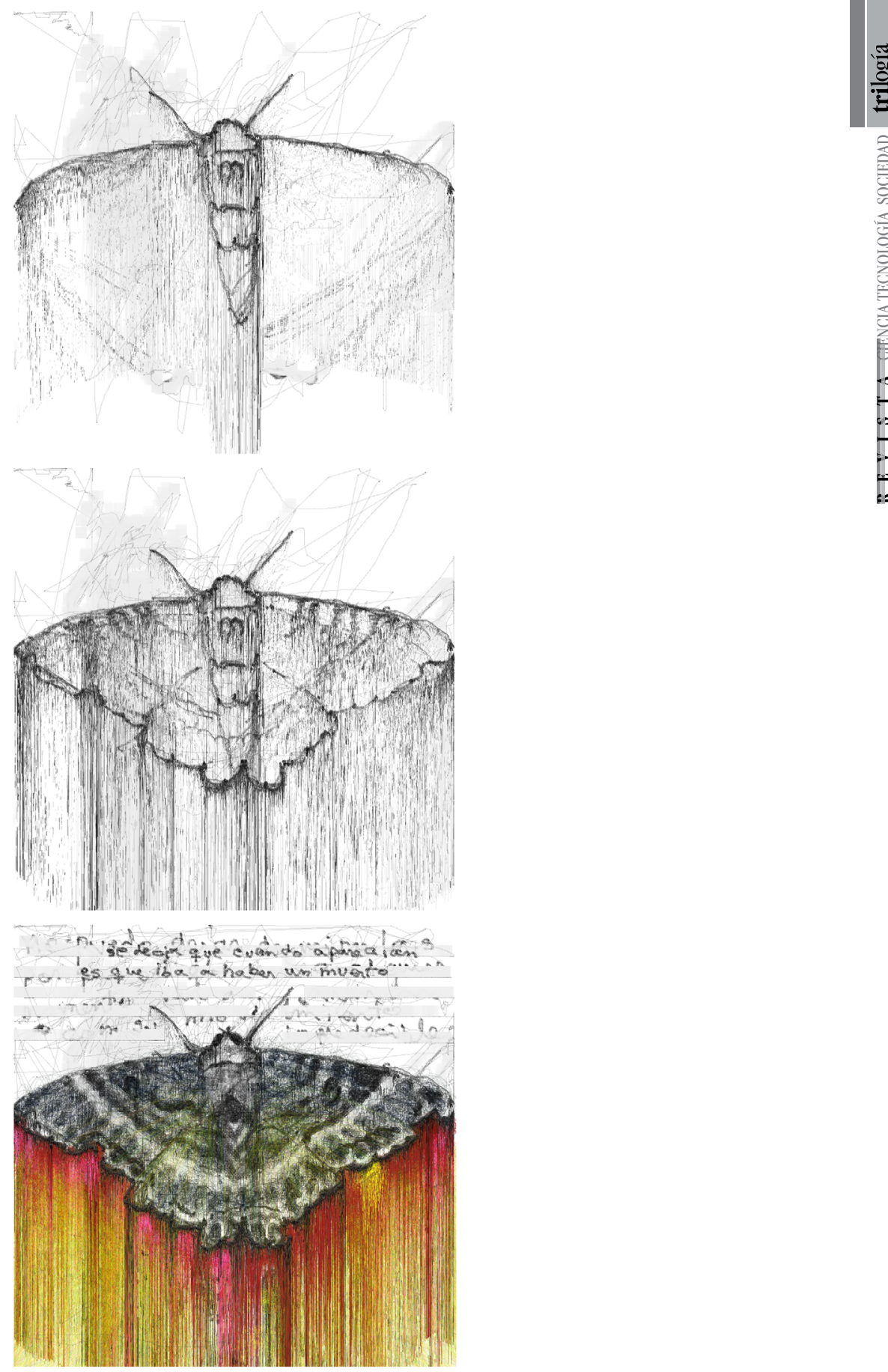

Fuente: elaboración propia.

Nota: Proyecto gráfico creado con programas desarrollados en Dibujo: búsquedas y apropiaciones. 
ACtualizaCiones visuales dinÁmicas en los Sistemas digitales

Material digital y creación artística es una investigación dónde se explora la relación entre los procesos creativos y los sistemas digitales en el contexto artístico colombiano. En este proyecto se define un modelo práctico para el material artístico que se usa en el contexto informático: el material digital. Dicho modelo es implementado para el análisis tecno-formal y metodológico de una serie de proyectos creativos que hacen uso de tecnologías digitales en diferentes instancias, una de las cuales está constituida por sus actualizaciones sensibles. El estudio se realizó a través de una serie de entrevistas y conversaciones con cuatro artistas de gran impacto nacional: Mario Opazo, Nelson Vergara, Andrés Burbano y David Peña. Estos intercambios permitieron definir las relaciones reales, en prácticas creativas particulares, entre el proceso de diseño, creación e implementación técnica. Una vez definida la posición de los creadores, se logró analizar una selección de sus obras a la luz del modelo de material digital y en particular las características de sus imágenes. En conclusión, se consiguió usar el modelo AVD para estudiar, diferenciar e interpretar los procesos creativos y su repercusión en los objetos y discursos visuales que dan cuerpo a las obras.

Porúltimo, Actualizaciones Visuales Dinámicas se ha alimentado de estas experiencias para desarrollar una nueva serie de programas informáticos que expanden el ámbito de acción del modelo. Este proyecto en curso revisa la fotografía y el video digital bajo el lente de las AVD, explora las estructuras tecno-conceptuales de los objetos informáticos que llamamos «fotografía» o «video» para reinterpretarlos mediante el código informático. En concreto, se han creado una serie de programas que usan los datos de este tipo de archivos y los transforman en paletas pictóricas o volúmenes tridimensionales. Sumado a esto, también se ha trabajado en el desarrollo de un programa que permite producir imágenes de alta resolución desde videos de menor resolución. La Imagen 2 presenta las gigantografías construidas por este medio para el proyecto de creación Distorsión (2018). En conclusión, este proyecto de investigación-creación aplica los resultados del modelo AVD en métodos de creación que permiten modificar y usar la información fotográfica en función de sus características digitales. 
Fuente: elaboración propia.

Nota: Gigantografías de alta resolución creadas mediante un programa que reorganiza los píxeles de un archivo de video en una sola imagen bidimensional. Cada imagen se construye con la información de 576 cuadros de video y tienen dimensión impresión de 3.5 x 2 metros.

\section{Vectores diferenciales}

Con el propósito de explorar la materialidad digital de las actualizaciones visuales, se plantean tres vectores diferenciales que las disocian de las imágenes convencionales: (1) Son procesuales, se actualizan constantemente mediante los datos generados en el diálogo archivo-sistema-usuario. (2) Son interactivas, pueden ser manipuladas en tiempo real dado que los datos generados por los usuarios están involucrados en el proceso que las genera. (3) Son temporales, denotan un estado transitorio de relaciones dinámicas. Estas tres características son importantes pues son evidencia de su materialidad digital. Facultan a las AVD del potencial para actualizarse en pantalla en una multiplicidad de lenguajes que incluyen: al texto, las imágenes estáticas, los vídeos, los mundos interactivos o las interfaces gráficas. Son reflejo de las cualidades del sistema problemático en que se generan y propias de su carácter digital. En definitiva, las AVD son el estrato 
de información más externo de los sistemas digitales, son parte de estos, y reflejan su lógica y estructura.

Dado que el material informático es esencialmente abstracto, pues los caminos de actualización de la información no están predefinidos en sus datos binarios, sus AVD no están preinscritas en él'; más bien, se reconstruyen constantemente en función del sistema de relaciones temporal entre material-sistema-usuario. Las condiciones del sistema pueden cambiar en cualquier momento, lo que genera también un cambio en las actualizaciones. Por ejemplo, el tamaño o resolución de la pantalla varía, la velocidad de procesamiento fluctúa o, incluso, la forma de uso se modifica. Como se ve, esta condición de abstracción produce actualizaciones sensibles procesuales y temporales, incluso en aquellos casos en que las AVD se leen como imágenes predigitales estables.

Esta aparente estabilidad de algunas AVD está asociada a una disposición interpretativa heredada de modelos heredados y no a su realidad digital. Si se toma por ejemplo una fotografía digital, es decir una imagen digital producida dentro de un sistema denominado cámara fotográfica, su lectura e interpretación se da en función del lenguaje fotográfico; se lee como la ampliación de un negativo químico. Esto es, como una imagen fija sobre un soporte estable, con unos atributos igualmente estables a la cual se puede acceder en cualquier momento, pues permanecerá invariable. En esta lectura pragmática de la información visual, prevalece la función discursiva heredada de la imagen fotográfica, obscureciendo las evidencias que contrarían dicha lectura. La actualización visual se lee como fotografía, adquiriendo automáticamente sus cualidades y su estabilidad, aun cuando en pantalla es evidente su variabilidad: cada vez que el archivo se abre cambia su tamaño en función del contenedor -ventana- en el que se abre; los colores de la imagen cambian según la pantalla en la que se visualiza; sobre la imagen aparecen elementos gráficos (textos, números, fechas, iconos, etc.) que cambian constantemente; o el hecho de que por lo general la imagen no ocupa la totalidad de la pantalla y por lo tanto se da en un contexto gráfico cambiante e inestable. Esta observación señala que, esa actualización visual de la información no contiene en sí misma los atributos que se le asignan en su lectura, para este ejemplo de imagen fotográfica. La limitada estabilidad de dicha AVD se encuentra

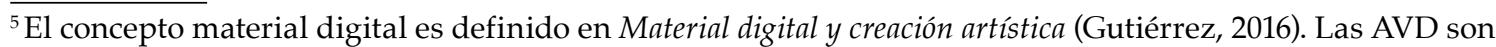
su expresión visual y es considerado aquello que el creador moldea y transforma en su proceso creativo dentro de los entornos digitales.
} 
en el sistema de relaciones predefinido en el que se actualiza y refleja de forma más efectiva el uso sociocultural que se le da en un momento determinado que su estructura informacional.

El segundo atributo de las AVD es su interactividad y está directamente relacionado con su constante actualización. Puesto que el sistema de relaciones que las genera está abierto a flujos de datos externos, la influencia de dichos datos afecta de forma directa su formalización. Retomando el ejemplo de las fotografías digitales, se puede apreciar que las acciones estándar del usuario computacional: abrir y cerrar programas, cambiar de tamaño o posición las ventanas o prender y apagar las pantallas, alteran el sistema de relaciones que produce las AVD en pantalla transformando sus relaciones visuales. Estas acciones indirectas alteran a las imágenes fotográficas pues cambian el equilibrio de su contexto $\mathrm{y}$, aunque no se den directamente sobre la entidad definida como «la imagen», sí transforman el resultado visual que se percibe. Este tipo de interacciones pueden ser descartadas en una aproximación funcional a la imagen, es decir, se puede asumir que la imagen no ha cambiado, empero, afectan de forma considerable la manera en que se consumen las imágenes en los entornos digitales.

También existen otras configuraciones del sistema que hacen uso profundo de potencial de procesamiento y de divergencia de los computadores. Los programas de edición gráfica o las aplicaciones que usan datos producidos por el usuario como parte de sus insumos, generan transformaciones directas sobre las AVD y pueden cambiar los valores específicos de sus pixeles. En estos casos, la formalización en pantalla ya no es resultado de los datos del archivo y su proceso de actualización predefinido. Se activa para el usuario la naturaleza dinámica del material digital y el carácter interactivo de sus actualizaciones. Su actuar y pensar produce datos que se mezclan con los de los archivos y el sistema para producir colecciones de datos completamente nuevos. Datos que no existían en el archivo original y que incluso no podían ser previstos a partir de él.

De esta forma, el atributo temporal de las actualizaciones se hace latente, pues las acciones del usuario sobre el sistema tienden a modificar la información visible en pantalla y en consecuencia las AVD. Las imágenes que se proyectan en pantalla están siendo reconstruidas constantemente, el proceso que las construye se repite en función de la incesante búsqueda de nuevos datos, por lo que las imágenes en pantalla se encuentran siempre acumulando una fuerza estática que al menor 
flujo de datos se traduce en la transformación de la pantalla. Esta fuerza latente de cambio es una expresión de la fuerza de convergencia que domina los procesos digitales en donde toda información tiende a ser convertida en pulsos eléctricos indiferenciables. También manifiesta el sentido divergente de dicha fuerza, pues, el estado temporal de los procesos de actualización contiene el potencial de transformarse en una cantidad indeterminada de versiones nuevas cuando el sistema de relaciones se ve alterado por un flujo nuevo de datos. Su carácter temporal también es consecuencia de los códigos no visuales de almacenaje en los sistemas digitales. Cuando la información visual es almacenada en un archivo de imagen, lo que se guarda es: valores numéricos, algoritmos y sistemas de relaciones en estructuras informacionales inaccesibles para el hombre a través de su sentido de la vista. En consecuencia, para recuperar y actualizar dicha información, la imagen se debe generar nuevamente a partir del sistema de relaciones actualizado. Por tanto, un archivo de imagen es tan solo una estructura informacional con el potencial de actualización visual.

Se puede apreciar que las actualizaciones sensibles reflejan la estructura de los sistemas digitales. Sus atributos son expresiones de las características de su materialidad digital y, simultáneamente, son parte de esta. Las actualizaciones sensibles son la última barrera de abstracción (Abelson, Sussman \& Sussman, 1996, p. 86) ${ }^{6}$, el módulo más externo, en donde la información cambia de naturaleza, se transforma en señales sensibles para el hombre: imágenes, sonidos, texto, etc. Estas señales sensibles son interpretadas por el hombre bajo parámetros culturales específicos que son los que le permiten integrarse al sistema.

\section{RESULTADOS}

\section{Modelo de las AVD}

Partiendo de las ideas desarrolladas hasta este punto, se pueden señalar unas pautas básicas que cumplen todas las actualizaciones visuales dinámicas: A) Las AVD solo existen dentro de los sistemas digitales. Cuando su información se extrae del sistema pierde sus características diferenciales. Por ejemplo, al imprimir una imagen a partir de un archivo digital se finaliza el proceso que la produce, se cierra el flujo de información, y se hace permanente en una superficie.

\footnotetext{
${ }^{6}$ Las barreras de abstracción son instancias en las que la naturaleza de los datos cambia su sentido contextual y su formato. Por ejemplo, los valores numéricos de un pixel se convierten en la potencia de un led.
} 
B) Las actualizaciones sensibles son sustanciales a la materialidad de las entidades digitales, pues a través de ellas se le hacen sensibles al hombre. De igual forma, son una instancia importante de interacción con estas entidades. Dado que la instancia binaria -y otras posibles- del material digital es indescifrable para un humano, es necesario que esa información se haga perceptible y comprensible para el hombre mediante sus actualizaciones. C) Dado que las relaciones con las AVD se producen dentro de un sistema digital, deben considerarse constitutivas del propio sistema, independientemente del tamaño o complejidad del mismo. Son su barrera de abstracción externa a través de la cual el hombre interactúa con la información interna.

Dentro de este marco general, las AVD son las actualizaciones sensibles de los sistemas digitales que se despliegan visualmente. Constituyen un tipo específico de formalización, pero su análisis es válido para otras posibles: sonoras, táctiles, textuales y más. En la actualidad dominan el espectro de posibles actualizaciones dentro de la infraestructura digital, así como el de la creación digital. Hay al menos tres grandes categorías dentro de las AVD: las llamadas imágenes digitales, las visualizaciones de datos y las interfaces gráficas de usuario (GUI), aunque cabe esperar el surgimiento de nuevas formas visuales. Este panorama general permite proyectar un modelo de base para el estudio y análisis de las actualizaciones sensibles, ilustrado en la Figura 1. La propuesta pretende resaltar las características de su digitalidad por encima de aquellas heredadas de lenguajes predigitales. Es importante enfatizar que el análisis de estos objetos culturales complejos se puede dar desde múltiples perspectivas, por lo cual el modelo propuesto no se considera en ningún momento autosuficiente, más bien es una herramienta que suma a la paleta conceptual disponible para su estudio.

A continuación, se realiza una descripción del modelo a la luz del esquema presentado en la Figura 1 y del ejemplo visual de la Figura 2. Sin embargo, el arquetipo puede ser implementado en la escala de diferentes configuraciones sistémicas y para actualizaciones sensibles de diferentes características y espectros sensibles. Para proseguir la demostración, se parte del sistema relacional configurado por: archivo de imagen, programa informático, computador personal y humano. Siendo así, la imagen proyectada en pantalla es el estado temporal visible de ese sistema y su análisis no debe limitarse únicamente en ella, pues es solo parte de un todo, de una entidad digital. Los estratos de información 
constitutivos de su materialidad digital se expresan en la estructura del archivo de imagen, su interacción con el sistema y su expresión gráfica en pantalla.

Figura 1. Modelo de los niveles de información expresados como AVD, material digital y estructura de software.

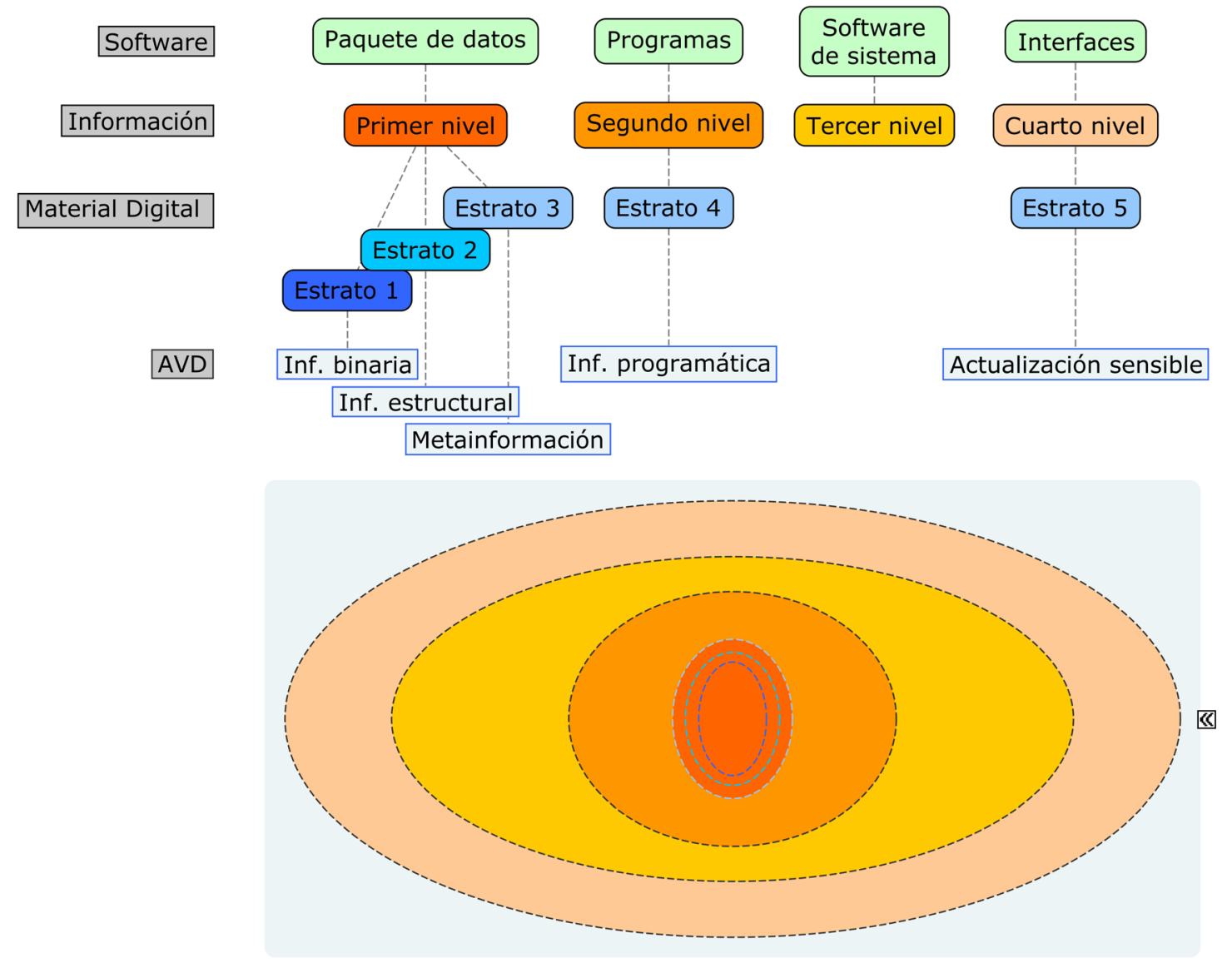

Fuente: elaboración propia.

La Figura 2 señala múltiples caminos de actualización que se pueden dar potencialmente desde un mismo archivo. El archivo de imagen IMG_3014.JPG ha sido obtenido con una cámara digital de fotografía. En consecuencia, su camino de actualización predefinido lo lleva hacia la representación fotográfica de un paisaje en un programa para visualizar imágenes en mapas de bits (A1). Aun así, es posible actualizar diferentes niveles de información del archivo, como por ejemplo su metainformación en un programa para visualizar las propiedades de un archivo (A6). También es posible actualizar la información visual en diferentes formas (A2, A3, A4) e incluyendo datos nuevos de la interacción con el usuario (A3 y A4). El ejemplo concluye actualizando los datos mediante la apertura del 
archivo de imagen con un programa para la edición de texto, lo cual genera una traducción de los datos a una estructura de caracteres alfanuméricos (A5).

Como se ve, el archivo de imagen es tan solo parte de lo que se conoce como imagen digital y la imagen en pantalla es tan solo una expresión temporal del archivo interactuando con el sistema. En consecuencia, las AVD son más que su proyección visual o su archivo informático, por esta razón su potencial expresivo sobrepasa el de otro tipo de imágenes. Diferentes formas de relación con las AVD utilizan datos de fuentes disímiles y los introducen en su actualización. Lo cual significa que un mismo archivo de imagen puede resultar en múltiples expresiones visuales o, también, que una misma secuencia de acciones sobre la imagen se manifieste de forma heterogénea, según el programa informático que gestiona dichas acciones. Incluso, es posible que un archivo de imagen se haga sensible en otro registro sensual, por ejemplo, una secuencia de caracteres alfanuméricos o un sonido.

Figura 2. Ejemplo de divergencia en la actualización de un archivo de imagen.

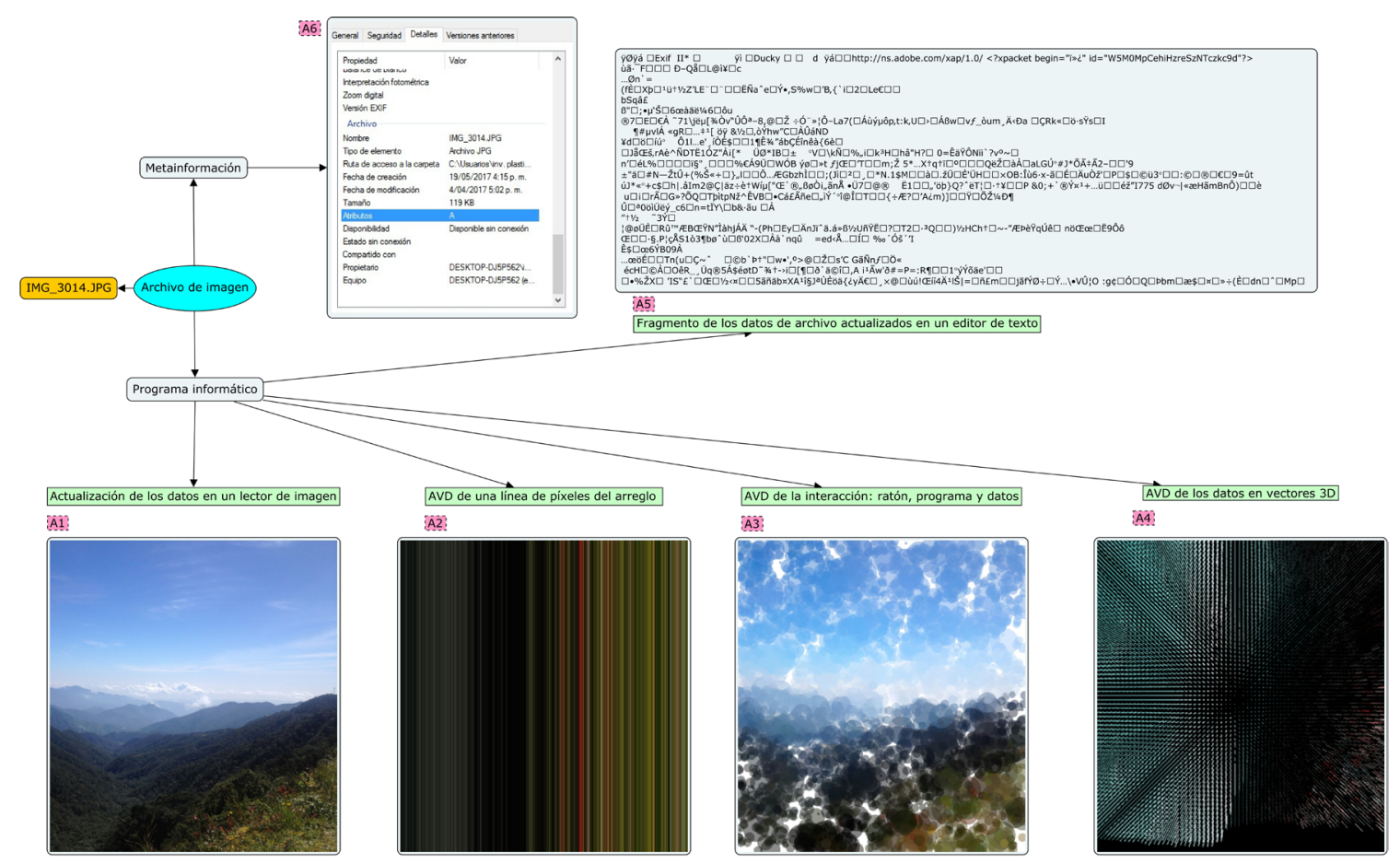

Fuente: elaboración propia. 
ACtualizaCiones visuales dinÁmicas en los Sistemas Digitales

El archivo IMG_3014.JPG se actualiza en función de la configuración e interacción entre: archivo-software-humano. En este caso se presentan cuatro usos diferentes de los datos que producen distintas AVD y un quinto caso en el cual su información se actualiza en registros no visuales, específicamente caracteres alfanuméricos producto de la lectura de datos en un procesador de texto.

\section{Estructura. Niveles y estratos}

El modelo propuesto está conformado por cinco estratos de información y cuatro niveles de acceso. Al revisarlo en función de una AVD, el archivo de imagen comprende la totalidad del primer nivel y se expresa visualmente en el estrato 5 tras interactuar con el resto de niveles. En la Tabla 1 se describe una configuración básica para un archivo digital de imagen.

Al revisar el modelo se encuentra que cada paquete de datos (generalmente identificado como un archivo y contenido en el Nivel 1) tiene asociados datos que definen el contenido de registro (Estrato 1) y datos de información extra (Estratos 2 y 3) que facilitan su manejo y que favorecen, pero no determinan, un tipo específico de actualización. Es decir, los datos en los estratos dos y tres informan al sistema sobre qué programas y módulos informáticos usar para obtener un resultado óptimo en la formalización de la información (Figura 2, actualización A1). Sin embargo, el acceso y control de dichos estratos, mediante los programas en el segundo nivel y cuarto estrato, permite manejar los datos en formas diversas y manipular el proceso de actualización para obtener AVD no convencionales, como se puede ver en la Figura 2 (actualizaciones A2, A3 o A4).

Los sistemas digitales están configurados para manejar los datos por intermedio de programas (Nivel 2) y módulos del sistema (Nivel 3) concretos conforme a su estructura informática y metadatos. Esto incluye, formalizar los datos de forma sensible en un tipo particular de interfaz de comunicación humana, que en este caso particular es la pantalla. Por lo tanto, aquello que se lee como una imagen digital es una actualización visual dinámica de un proceso que involucra: la lectura de un paquete de datos abstracto a través de procesos informáticos; la manipulación de dichos datos mediante programas; la circulación de la información a través de la configuración particular del sistema y, potencialmente, la interacción con datos nuevos (interacción humana, Nivel 4). 
Tabla 1. Estratos de información y niveles de acceso a los datos que formalizan la materialidad digital de las AVD

\begin{tabular}{|c|c|c|}
\hline \multicolumn{2}{|c|}{ Niveles y estratos de la información } & Datos específicos para el modelo en las AVD \\
\hline NIVEL 1 & | ---------' | & Archivo de imagen digital \\
\hline Estrato 1 & | --------------- | & $\begin{array}{l}\text { Información binaria o numérica } \\
\text { Matriz numérica que contiene los valores de los pixeles o los vectores } \\
\text { y demás datos que conforman la imagen. }\end{array}$ \\
\hline Estrato 2 & | --------------- | & $\begin{array}{l}\text { Información estructural o cabecera } \\
\text { Contiene la información necesaria para decodificar la información } \\
\text { del primer estrato. Por ejemplo, las dimensiones de la imagen, el tipo } \\
\text { de codificación o la profundidad de color. }\end{array}$ \\
\hline Estrato 3 & | --------------- | & $\begin{array}{l}\text { Metainformación } \\
\text { Contiene información externa a la propia imagen, pero relacionada } \\
\text { con esta. Por ejemplo, fecha de creación, sistemas involucrados o datos } \\
\text { del creador. Aunque esta información no es usada directamente para } \\
\text { proyectar la imagen es indispensable para el manejo de volúmenes } \\
\text { significativos de archivos. }\end{array}$ \\
\hline \multicolumn{3}{|c|}{$\downarrow \downarrow \downarrow \downarrow \downarrow \downarrow \downarrow \downarrow \downarrow$} \\
\hline NIVEL 2 & | ---------- | & $\begin{array}{l}\text { Programas } \\
\text { Aplicaciones específicas para manejar, modificar o visualizar este } \\
\text { tipo de archivos. }\end{array}$ \\
\hline Estrato 4 & | --------------- | & $\begin{array}{l}\text { Información programática } \\
\text { Código para el manejo de los archivos de imagen. Incluye el acceso } \\
\text { a los estratos del primer nivel y su interacción con otros archivos o } \\
\text { flujos de información. También la posibilidad de generar información } \\
\text { desde el propio código. }\end{array}$ \\
\hline \multicolumn{3}{|c|}{$\downarrow \downarrow \downarrow \downarrow \downarrow \downarrow \downarrow \downarrow \downarrow$} \\
\hline NIVEL 3 & | --------- | & $\begin{array}{l}\text { Software de sistema } \\
\text { Comprende el sistema operativo y otras aplicaciones de gestión, } \\
\text { transcodificación y manejo. }\end{array}$ \\
\hline \multicolumn{3}{|c|}{$\downarrow \downarrow \downarrow \downarrow \downarrow \downarrow \downarrow \downarrow \downarrow$} \\
\hline NIVEL 4 & |--------- | & Interfaces de comunicación humana \\
\hline Estrato 5 & | --------------- | & $\begin{array}{l}\text { Información sensible } \\
\text { Actualizaciones visuales dinámicas de la interacción entre los cuatro } \\
\text { niveles, en definitiva, la proyección en pantalla o lo que se denomina } \\
\text { imagen digital. }\end{array}$ \\
\hline
\end{tabular}

Fuente: elaboración propia.

Los sistemas digitales están configurados para manejar los datos por intermedio de programas (Nivel 2) y módulos del sistema (Nivel 3) concretos conforme a su estructura informática y metadatos. Esto incluye, formalizar los datos de forma sensible en un tipo particular de interfaz de comunicación humana, que en este caso particular es la pantalla. Por lo tanto, aquello que se lee como una imagen digital es una actualización visual dinámica de un proceso que involucra: la lectura de un paquete de datos abstracto a través de procesos informáticos; la manipulación 
de dichos datos mediante programas; la circulación de la información a través de la configuración particular del sistema y, potencialmente, la interacción con datos nuevos (interacción humana, Nivel 4).

En general, los datos del archivo están predefinidos y son la única instancia estable del conjunto. Interactúan con los demás niveles de información para finalmente proyectase como un arreglo de pixeles en una pantalla de características indefinidas. Como se ha señalado, las relaciones que se producen en el proceso de actualización son altamente variables, pero incluso en aquellos casos donde no se generan datos nuevos ni interacción, las AVD varían en función de las características de la infraestructura tecnológica del sistema en que se producen.

Por último, cabe señalar que aunque existen procesos informáticos predefinidos asociados a formatos de archivos específicos, el trabajo creativo con la información no está supeditado a estos procesos. Los caminos de actualización pueden ser modificados, o cambiar por completo, en conformidad con las intenciones del usuario. No existe una relación de continuidad entre un paquete de datos $\mathrm{A}$ y una actualización $\mathrm{C}$ mediados por un sistema relacional B. Lo cual indica que el análisis de una AVD desde su expresión visual es tan incompleto como el análisis de la estructura informática de su archivo fuente.

A diferencia de las imágenes predigitales, las actualizaciones sensibles son independientes del sistema de relaciones primario y es posible generar nuevos caminos. Por ejemplo, en la Figura 2, un archivo de imagen (un paquete de datos que favorece a la imagen como actualización) puede producir una secuencia alfanumérica (actualización A5), alejándose por completo de la representación visual y abriendo nuevos caminos sensibles y de interpretación. Es en las interacciones gestadas en los procesos actualizadores que se produce el vínculo y se integra el pensamiento creativo. Por lo tanto, este proceso dinámico debe ser incluido en el análisis de los productos culturales digitales, ya que en él se definen, potencian $\mathrm{u}$ ocultan las características de su materialidad digital y se revela el pensamiento del creador. 


\section{CONCLUSIÓN} (fotografías, visualizaciones, videos, alzados vectoriales, entre otras), desde su sistema relacional para explorar de forma efectiva sus características digitales. Los niveles de acceso en el modelo definen posibles barreras de abstracción desde donde se moldea a la información. Los estratos expresan diferentes tipos de datos disponibles para el creador, quien puede leerlos desde su lógica medial o transformarlos para mapearlos en nuevas estructuras sensibles y simbólicas. Además, el modelo es un módulo conceptual que puede articularse con modelos tradicionales de análisis visual dado que, como se vio, las AVD heredan las construcciones discursivas, comunicacionales y de consumo de los lenguajes que simulan.

Por último, el modelo es capaz de proyectar diferentes prácticas creativas que implementan sistemas digitales puesto que comprende la actualización como una entidad en la que se aglutina desde la instancia binaria hasta la instancia sensible, incluyendo la interacción humana. Los vectores diferenciales propuestos (procesualidad, interactividad y temporalidad) permiten estudiar la forma heterogénea en que son usados, manipulados y leídos estos objetos culturales. En su estudio se evidencian las prácticas creativas, ya que, éstas definen la manera en que se explota o apaga el potencial expresivo de cada uno de estos vectores. Esta propuesta pretende trazar un puente entre los sistemas digitales, que se reflejan en su estructura, y el lenguaje visual, expresado en la articulación de los vectores con el análisis de otros modos de producción visual. 
ACtualizaCiones visuales dinÁmicas en los Sistemas Digitales

\section{REFERENCIAS}

Abelson, H., Sussman, G. J., \& Sussman, J. (1996). Structure and interpretation of computer programs. Cambridge, Mass.: MIT.

Arns, I. (2013). Feeding the Serpent Its Own Tail: Counterforces to Tactile Enclosure in the Age of Transparency. Throughout: Art and Culture Emerging with Ubiquitous Computing, 385.

Cramer, F. (2002). Concepts, notations, software, art. In Seminar for Allegmeine und Vergleischende Literaturwissenschaft. Berlin: Freie Universität Berlin. Recuperado de http:/ / www.cramer.pleintekst.nl/all/ concept_notations_software_art/ concepts_notations_software_art.pdf

Gutiérrez, E. (2006). El dibujo: búsquedas y apropiaciones. Bogotá: Universidad Nacional de Colombia.

Gutiérrez, E. (2007). DBA-El cuerpo: Interfaces físicas. Barcelona: MECAD.

Gutiérrez, E. (2016). Material Digital y creación artística. Bogotá: Universidad Nacional de Colombia. Recuperado de http://www.bdigital.unal.edu. co/54303/\#sthash.kwuvxKbP.pdf

Jenkins, H. (2008). Convergence Culture / Convergence Culture: la cultura de la convergencia de los medios de comunicacion/ Where Old and New Media Collide. Barcelona: Paidós.

Lévy, P. (1999). ¿Qué es lo virtual? Barcelona; Buenos Aires; México: Paidós.

Tanimoto, S. L. (2012). An Interdisciplinary Introduction to Image Processing: Pixels, Numbers, and Programs. Cambridge, Mass.: The MIT Press. 